Check for updates

Cite this: Chem. Commun., 2020, 56, 10477

Received 2nd June 2020,

Accepted 30th July 2020

DOI: $10.1039 / \mathrm{d} 0 \mathrm{cc} 03863 f$

rsc.li/chemcomm

\section{Role of electrolyte composition on the acid stability of mixed-metal oxygen evolution catalysts $\dagger$}

\author{
Nancy Li, Thomas P. Keane, Samuel S. Veroneau and Daniel G. Nocera (D)*
}

Acid stability in catalysts that promote the oxygen evolution reaction (OER) may be achieved through either the introduction of electrolyte-modulated self-healing processes, or the fixation of OER active sites within stable, conductive oxide matricies. By varying the nature of the electrolyte, $\mathrm{pH}$, buffer concentration, and ionic strength, the contributions of these two effects may be deconvoluted. Furthermore, we find that the nature of the buffer is capable of engendering OER with exceptional acid stability at moderate overpotentials.

The use of sunlight to produce liquid fuels directly from $\mathrm{CO}_{2}$ is an important strategy to diversifying the global fuel supply in a renewable and sustainable manner. ${ }^{1-4}$ Viable solar-generated liquid fuel processes must proceed at appreciable rates, at high energy efficiency (low overpotential) and with high carbon atom economy. While $\mathrm{CO}_{2}$ reduction to fuels has been demonstrated at synthetically relevant rates, ${ }^{5}$ the process confronts the limitation of low carbon efficiency owing to the non-faradaic reaction of $\mathrm{HO}^{-}$with $\mathrm{CO}_{2}$ to produce super-stoichiometric amounts of carbonate, severely compromising the atom efficiency of $\mathrm{CO}_{2}$-to-fuels catalysis. ${ }^{6}$ As has recently been demonstrated, a cell equilibrium is established with the complete consumption of $\mathrm{HO}^{-}$by $\mathrm{CO}_{2}$ to produce a purely bicarbonate electrolyte. ${ }^{7}$ This acid-base chemistry results in a loss of cell voltage and, more importantly, in extremely low $\mathrm{CO}_{2}$-to-fuel carbon yields. The time for such conversion to carbonate depends on a cell's reservoir of hydroxide, giving rise to a characteristic S-curve where this hydroxide reservoir absorbs $\mathrm{CO}_{2}$ until base is depleted, after which there is a rapid rise and then levelling upon concentration of a pure carbonate electrolyte. Cells reporting high current density are typically operated for shorter times than this transition to steady-state and consequently do not reflect the actual equilibrium conditions

Department of Chemistry and Chemical Biology, Harvard University, Cambridge, MA 02138, USA. E-mail: dnocera@fas.harvard.edu

$\dagger$ Electronic supplementary information (ESI) available: Experimental details and additional tables and figures. See DOI: 10.1039/d0cc03863f confronting a viable solar to liquid fuels process. Thus, the $\mathrm{CO}_{3}{ }^{2-}$ problem is currently the greatest single obstacle to achieving a viable photoelectrochemical fuels synthesis.

Carbonate formation may be mitigated by performing the $\mathrm{CO}_{2}$ reduction reaction $\left(\mathrm{CO}_{2} \mathrm{RR}\right)$ in acidic solutions, thus providing an imperative for the design of acid stable catalysts for the anodic reaction (i.e., the oxygen evolution reaction, OER), which provides reducing equivalents and protons for $\mathrm{CO}_{2} \mathrm{RR}$. We have developed OER catalysts based on cobalt ${ }^{8}$ and nickel ${ }^{9}$ that can drive OER in water $(\mathrm{pH}>5)$ with rapid kinetics and good energy efficiency. In more acidic conditions $(\mathrm{pH}<5)$, we have further shown that, by tuning the chemistry of selfhealing, ${ }^{10}$ metallate oxygen evolving catalysts (M-OECs) may be stabilized in acidic solution. ${ }^{11}$ This stability may be enhanced further by embedding M-OECs in acid-stable metal oxide frameworks, such as $\mathrm{MnO}_{x}$ or $\mathrm{PbO}_{x}{ }^{12}$ Using this approach, a series of acid-stable mixed-metal OECs, including $\mathrm{CoFePbO}_{x}$, are able to maintain activity at $\mathrm{pH} 2.5$ for $>30 \mathrm{~h}$. In such systems, the electrolyte plays an active role as a proton mediator for OER as well as a structural element in establishing the equilibrium needed for the self-healing of embedded active sites. We report herein studies seeking to explicitly define the role of electrolyte composition on film stability by comparing the OER activity of CoFePbO $x$ in phosphate $\left(\mathrm{H}_{3} \mathrm{PO}_{4} / \mathrm{KH}_{2} \mathrm{PO}_{4}, \mathrm{KP}_{\mathrm{i}}\right)$ and sulphate $\left(\mathrm{KHSO}_{4} / \mathrm{K}_{2} \mathrm{SO}_{4}, \mathrm{KS}_{\mathrm{i}}\right)$, as these electrolytes possess similar chemical forms and $\mathrm{p} K_{\mathrm{a}} \mathrm{s}\left(\mathrm{p} K_{\mathrm{a} 1}\left(\mathrm{H}_{3} \mathrm{PO}_{4}\right)=2.15\right.$ while $\left.\mathrm{p} K_{\mathrm{a} 2}\left(\mathrm{H}_{2} \mathrm{SO}_{4}\right)=2.00\right) .{ }^{13}$ We find that modulating the nature, concentration and $\mathrm{pH}$ of the electrolyte allows us to discern the contributions of self-healing and matrix-stabilization to catalyst longevity. Moreover, as an outgrowth of these studies, we find that when operated in sulphate buffer (in the absence of phosphate), the $\mathrm{PbO}_{x}$ framework can facilitate OER with exceptional acid stability at moderate overpotentials.

$\mathrm{CoPbO}_{x}$ and $\mathrm{CoFePbO}_{x}$ catalysts exhibit similar morphologies, as observed by SEM images of electrodeposited films, which are distinct from that of the filamentous $\mathrm{PbO}_{x}$ matrix (Fig. 1). EDS mapping indicates that the component metals are distributed homogeneously throughout the catalyst films 


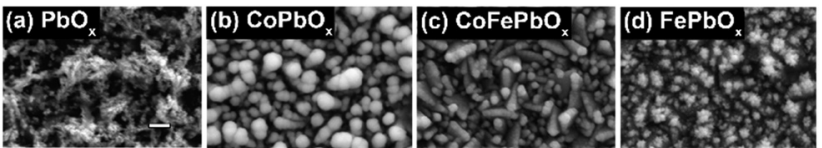

Fig. 1 SEM images of (a) $\mathrm{PbO}_{x}$ (b) $\mathrm{CoPbO}_{x}$ (c) $\mathrm{CoFePbO}$, and (d) $\mathrm{FePbO}_{x}$ for comparison. All samples were prepared on FTO substrate, and scale bar indicates $300 \mathrm{~nm}$.

(Fig. S1, ESI $\dagger$ ). Both films in $\mathrm{P}_{\mathrm{i}}$ and $\mathrm{S}_{\mathrm{i}}$ perform OER with faradaic efficiencies of $100 \%$.

Chronopotentiometry measurements were performed on $\mathrm{CoFePbO}_{x}$ films at a constant current of $1 \mathrm{~mA} \mathrm{~cm}{ }^{-2}$. The films were immersed in stirred solutions containing either $100 \mathrm{mM}$ of $\mathrm{KP}_{\mathrm{i}}, 100 \mathrm{mM}$ of $\mathrm{KS}_{\mathrm{i}}$, or $100 \mathrm{mM}$ each of $\mathrm{KP}_{\mathrm{i}}$ and $\mathrm{KS}_{\mathrm{i}}$. All solutions were buffered to $\mathrm{pH} 2.15$ and contained enough $\mathrm{KNO}_{3}$ supporting electrolyte to ensure a total ionic strength of $1.1 \mathrm{M}$. Representative chronopotentiometric traces are shown in Fig. 2. After a brief initial capacitive period, the operating potential for $\mathrm{CoFePbO}_{x}$ films settled at $\sim 1.6 \mathrm{~V}$ vs. NHE, at which OER was sustained ( $0.5 \mathrm{~V}$ overpotential for water splitting at $\mathrm{pH}=2.15$ ). After a period of operation, the film potentials underwent an inflection, rising rapidly before plateauing at an overpotential of $0.7 \mathrm{~V}$ for $\mathrm{KS}_{\mathrm{i}}$ or $1.6 \mathrm{~V}$ for $\mathrm{KP}_{\mathrm{i}}$ and $\mathrm{KP}_{\mathrm{i}} / \mathrm{KS}_{\mathrm{i}}$ electrolytes, indicative of OER at the $\mathrm{PbO}_{x}$ matrix in $\mathrm{KS}_{\mathrm{i}}$ and FTO substrate in $\mathrm{KP}_{\mathrm{i}}$, respectively. Direct $\mathrm{O}_{2}$ measurements for $\mathrm{CoFePbO}_{x}$ films operated in $\mathrm{KP}_{\mathrm{i}}$ and $\mathrm{KS}_{\mathrm{i}}$ electrolyte solutions before and after inflection show $100 \%$ faradaic efficiency for OER, ruling out the possibility of unproductive oxidation reactions. Hence, the inflection time was used as a metric for film stability. On this basis, films operated in solutions buffered with $100 \mathrm{mM} \mathrm{KP_{i }}$ display extended stability at lowest overpotential as compared to those buffered with $100 \mathrm{mM} \mathrm{KS}_{\mathrm{i}}$.

Film stability was examined for $\mathrm{KP}_{\mathrm{i}}$ and $\mathrm{KS}_{\mathrm{i}}$ electrolyte concentrations of $100 \mathrm{mM}$ and $250 \mathrm{mM}$ and at different pHs (Fig. S2, $\mathrm{ESI} \dagger$ ). For different concentrations of electrolyte, the overall buffer capacity was conserved in each electrolyte (see ESI $\dagger$ ). At a concentration of $100 \mathrm{mM}$ at $\mathrm{pH} 2.15, \mathrm{KP}_{\mathrm{i}}$ and $\mathrm{KS}_{\mathrm{i}}$ buffers have a buffer capacity, $\beta$, of 0.074 and 0.072 , respectively. At a concentration of
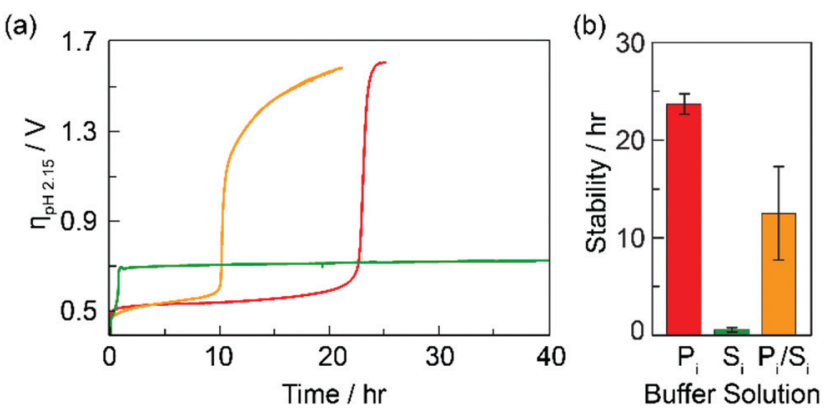

Buffer Solution

Fig. 2 Stability of $\mathrm{COFePbO}_{x}$ films performing OER at $1 \mathrm{~mA} \mathrm{~cm}{ }^{-2}$ in buffer solutions $(\mathrm{pH} 2.15)$ of $1 \mathrm{M} \mathrm{KNO}_{3}+0.1 \mathrm{M} \mathrm{KP}_{\mathrm{i}}\left(\right.$ red, $\left.\mathrm{P}_{\mathrm{i}}\right), 1 \mathrm{M} \mathrm{KNO}_{3}+0.1 \mathrm{M} \mathrm{KS}$ (green, $\mathrm{S}_{\mathrm{i}}$ ), or $0.8 \mathrm{M} \mathrm{KNO}_{3}+0.1 \mathrm{MK \textrm {K } _ { \mathrm { i } }}+0.1 \mathrm{M} \mathrm{KS}_{\mathrm{i}}$ (orange, $\mathrm{P}_{\mathrm{i}} / \mathrm{S}_{\mathrm{i}}$ ): (a) chronopotentiometry curves, and (b) bar graphs indicating average stability (time required to reach the plateau current). $\eta_{\mathrm{pH} 2.15}=E_{\mathrm{appl}}-E_{\text {therm }}$ where $E_{\text {therm }}$ is the thermodynamic potential for water splitting at $\mathrm{pH}=2.15$ and $E_{\text {appl }}=$ applied potential.
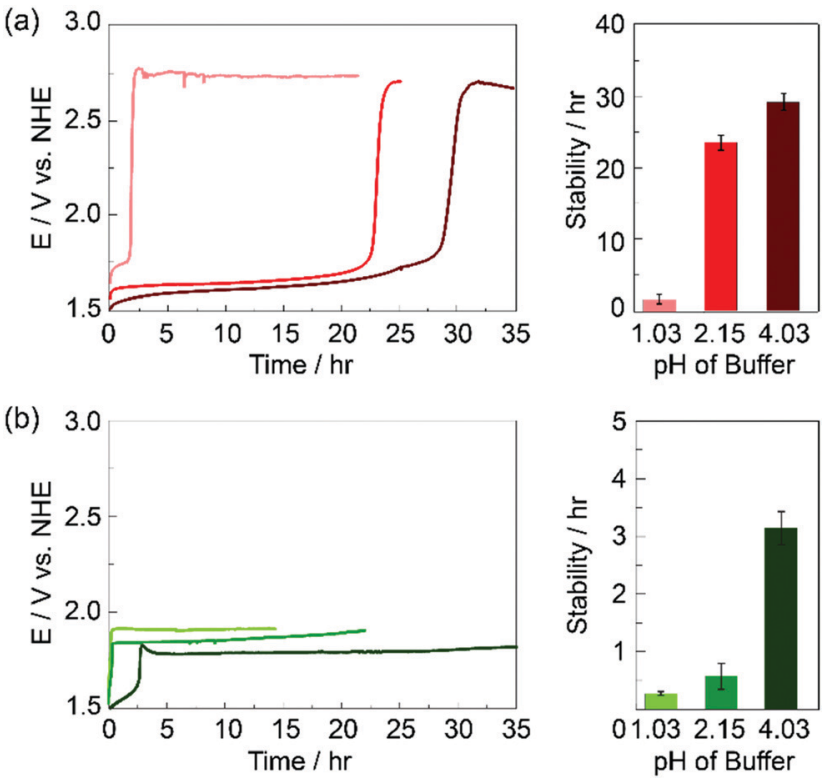

Fig. 3 Stability of $\mathrm{COFePbO}_{x}$ films performing $\mathrm{OER}$ at $1 \mathrm{~mA} \mathrm{~cm}{ }^{-2}$ in solutions containing (a) $1 \mathrm{M} \mathrm{KNO}_{3}+0.1 \mathrm{M} \mathrm{KP}_{\mathrm{i}}$ and (b) $1 \mathrm{M} \mathrm{KNO}_{3}+0.1 \mathrm{M} \mathrm{KS}_{\mathrm{i}}$ at different $\mathrm{pH}: 1.03$ (light red and light green), $\mathrm{pH} 2.15$ (red and green), and pH 4.03 (dark red and dark green). Representative chronopotentiometry curves (left), and bar graphs indicating average film stabilities (right) at each $\mathrm{pH}$ are shown.

$250 \mathrm{mM}$ at $\mathrm{pH} 2.15, \mathrm{KP}_{\mathrm{i}}$ and $\mathrm{KS}_{\mathrm{i}}$ buffers have a buffer capacity of 0.160 and 0.156 , respectively. For both $\mathrm{KP}_{\mathrm{i}}$ and $\mathrm{KS}_{\mathrm{i}}$, increasing buffer concentration led to a marginal decrease in film stability. This change cannot be attributed to ionic strength differences, as experiments performed in the presence of $1 \mathrm{M} \mathrm{KNO}_{3}$ showed no difference in the stability of the film in the presence of $\mathrm{KP}_{\mathrm{i}}$ whereas $\mathrm{KS}_{\mathrm{i}}$ exhibited a slight decrease as compared to experiments run in the absence of $\mathrm{KNO}_{3}$. More profound was the effect of $\mathrm{pH}$ on film stability. Representative chronopotentiometry curves and average film stability times at $\mathrm{pH} 1.03,2.15$ and 4.03 are shown in Fig. 3. For both electrolyte systems, film stability during OER operation decreased with decreasing $\mathrm{pH}$; films operating in $S_{i}$ exhibited significantly more instability than films operated in $\mathrm{P}_{\mathrm{i}}$. For these films, a precipitous drop in stability is observed between $\mathrm{pH} 2.15$ and $\mathrm{pH} 1.03$, consistent with the essential role of monobasic phosphate in promoting self-healing (vide infra).

We compared the elemental composition of films before and after OER in different electrolyte solutions using ICP-MS (see ESI $\dagger$ for experimental details). The results of these experiments are summarized in Fig. 4 (Table S1, ESI $\dagger$ ). For both $\mathrm{KP}_{\mathrm{i}}$ and $\mathrm{KS}_{\mathrm{i}}$ electrolytes, film composition does not change significantly from the as-deposited film within the first $10 \mathrm{~min}$ of OER. Following 40 hours of electrolysis (post-inflection for all buffer conditions) all films exhibited significant metal loss. Films operated in $\mathrm{KP}_{\mathrm{i}}$ electrolyte lose approximately $50 \%$ of their Fe content, $75 \%$ of their Co content, and $45 \%$ of their $\mathrm{Pb}$ content ( $v s$. as-deposited films). This metal loss does not appear to change with addition of $\mathrm{KNO}_{3}$ or at higher concentrations of $\mathrm{KP}_{\mathrm{i}}$. Similarly, Co loss is also observed and in even greater mangitude (88\%) for $\mathrm{CoFePbO}_{x}$ films operated in $\mathrm{KS}_{\mathrm{i}}$. Interestingly, however, 


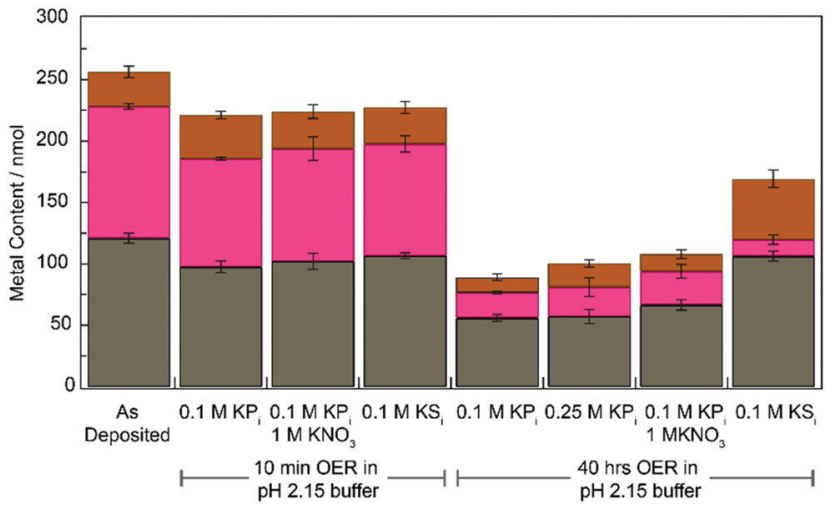

Fig. 4 Total metal content, $\mathrm{Pb}$ (grey), Fe (brown), and Co (magenta) of $1 \mathrm{~cm}^{2} \mathrm{CoFePbO}_{x}$ films after operation in specified buffers at $\mathrm{pH} 2.15$ for $0 \mathrm{~min}, 10 \mathrm{~min}$, or $40 \mathrm{~h}$ at $1 \mathrm{~mA} \mathrm{~cm}{ }^{-2}$ for OER.

no $\mathrm{Fe}$ or $\mathrm{Pb}$ loss is observed for $\mathrm{CoFePbO}_{x}$ films operated in $\mathrm{KS}_{\mathrm{i}}$. The increased loss of $\mathrm{Pb}$ from films operated in $\mathrm{KP}_{\mathrm{i}}$ relative to $\mathrm{KS}_{\mathrm{i}}$ may reflect the formation of soluble $\mathrm{Pb}$ (Iv) phosphate complexes, which have been reported to form electrochemically via oxidation of $\mathrm{PbO}_{2}$ in the presence of phosphoric acid. ${ }^{14}$ Formation of the corresponding sulphate complexes has not been observed.

The disparate behaviour exhibited by $\mathrm{CoFePbO}_{x}$ films operated in acidic $\mathrm{KP}_{\mathrm{i}}$ and $\mathrm{KS}_{\mathrm{i}}$ solutions is consistent with stabilization of the catalyst active site by (1) electrolyte-driven self-healing of active sites and (2) matrix stabilization of active sites within the $\mathrm{PbO}_{x}$ framework. The work described herein now enables us to disentangle the role of self-healing and matrix stabilization in acidic media.

With regard to (1) active site stabilization via self-healing, pair distribution functional (PDF) analysis of $\mathrm{CoP}_{\mathrm{i}}$ films shows the catalyst to be composed of oxidic metallate clusters of 10-14 Co atoms. ${ }^{15-17}$ The active sites have been shown to self-heal ${ }^{10,18}$ where their self-assembly is balanced with OER such that the driving force required for self-assembly (i.e., catalyst regeneration) lies energetically within that for OER catalysis. For Co oxidic metallate clusters, when operating in acidic environments, the self-assembly process cannot be maintained owing to an inverse third-order dependence on proton activity, ${ }^{19}$ thus moving the catalyst system out of a regime of stability and imposing a limited operating lifetime on the catalyst. At pH 2.15, the dominant bases in $\mathrm{P}_{\mathrm{i}}$ and $\mathrm{S}_{\mathrm{i}}$ are $\mathrm{H}_{2} \mathrm{PO}_{4}{ }^{-}$and $\mathrm{SO}_{4}{ }^{2-}$, respectively, both of which are weak proton acceptors with similar basicity, and consequently neither is able to facilitate the deposition of $\mathrm{CoP}_{\mathrm{i}}$ at the same rate as $\mathrm{HPO}_{4}{ }^{2-}$. However, PDF analysis and reaction kinetics have shown that phosphate acts as a structural element that caps the edges of the metallate clusters $^{20}$ and hence provides added protection to the edge sites of the metallate clusters against protonation, thus shifting the equilibrium back towards self-assembly of the metallate active sites by impeding dissolution of the active sites during catalyst operation. This structural role of the buffer is further emphasized by the differing stability of $\mathrm{CoFePbO}_{x}$ in $\mathrm{KP}_{\mathrm{i}}$ and $\mathrm{KS}_{\mathrm{i}}$. The $\mathrm{P}_{\mathrm{i}}$ electrolyte is known to bind oxide surfaces with higher affinity via an inner-sphere (i.e., hydrogen bonding)

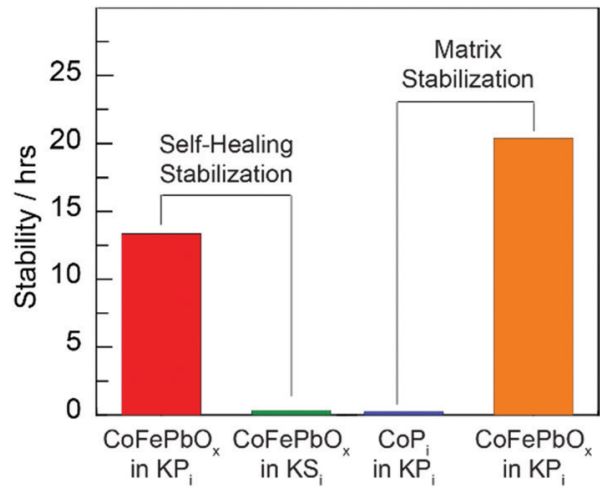

Fig. 5 Stability ascribed to (left) self-healing by comparison of $\mathrm{CoFePbO}_{x}$ films operating at $1 \mathrm{~mA} \mathrm{~cm}{ }^{-2}$ in $1 \mathrm{M} \mathrm{KNO}_{3}$ and either $0.25 \mathrm{M} \mathrm{KP}_{\mathrm{i}}$ (red) or

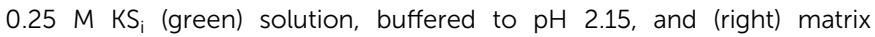
stabilization by comparison of $\mathrm{CoP}_{i}$ (blue) and $\mathrm{CoPbO}_{x}$ (orange) films operating at $1 \mathrm{~mA} \mathrm{~cm}{ }^{-2}$ in a $1 \mathrm{M} \mathrm{KNO}_{3}, 0.25 \mathrm{M} \mathrm{KP}_{\mathrm{i}}$, solution, buffered to $\mathrm{pH} 2.5$ (ref. 12)

mechanism..$^{21,22}$ Previous work has also shown that adsorbed phosphate is capable of stabilizing various metal oxide surfaces against corrosion. ${ }^{23,24}$ In contrast, $\mathrm{S}_{\mathrm{i}}$ has a significantly lower affinity for oxides, and studies have found evidence for an outer-sphere (i.e., ionic) mode of adsorption by sulphate onto these surfaces. ${ }^{25-27}$

With regard to (2) matrix stabilization, the comparison of $\mathrm{CoP}_{\mathrm{i}}$ and $\mathrm{CoFePbO}_{x}$ in Fig. 5 demonstrates the effect of the lead oxide matrix in enhancing acid stability. Elemental composition data summarized in Fig. 4 reveal sustained resistance of the $\mathrm{PbO}_{x}$ matrix to corrosion, further reinforcing the role of $\mathrm{PbO}_{x}$ as a stable structural component.

The chronopotentiometric trace in Fig. 2a for $\mathrm{CoFePO}_{x}$ in $\mathrm{S}_{\mathrm{i}}$ is intriguing, and highlights the important role that electrolyte can have on OER film stability and activity. The trace begins at an overpotential similar to that observed for $\mathrm{CoFePbO}_{x}$ in $\mathrm{P}_{\mathrm{i}}$. After approximately $1 \mathrm{~h}$, the operating potential rises, consistent with the loss of Co from the film (Fig. 4) and the trace stabilizes at an overpotential of $0.7 \mathrm{~V}$, which is almost $1 \mathrm{~V}$ lower than that observed for films operated in $\mathrm{KP}_{\mathrm{i}}$ following similar Co loss. Control experiments indicate that this potential is representative of OER on a $\mathrm{PbO}_{x}$ film when operated in $\mathrm{KS}_{\mathrm{i}}$ buffer (Fig. S3, $\mathrm{ESI} \dagger$ ). When $\mathrm{PbO}_{x}$ is operated at a similar $\mathrm{pH}$, but in the presence of $\mathrm{KP}_{\mathrm{i}}$, a $1.7 \mathrm{~V}$ overpotential is required to achieve the same current density. ${ }^{12}$ Though $\mathrm{PbO}_{x}$ in $\mathrm{KS}_{\mathrm{i}}$ requires a higher overpotential for OER than $\mathrm{CoFePbO}_{x}$, it is exceedingly stable in acid, maintaining activity for over $150 \mathrm{~h}$ with no sign of degradation (Fig. S4, ESI $\dagger$ ). The stark contrast in operating potentials for $\mathrm{PbO}_{x}$ in $\mathrm{KP}_{\mathrm{i}}$ versus $\mathrm{KS}_{\mathrm{i}}$ may result from differences in oxide surfacebinding between phosphate and sulphate, as described above. Notably, a similar explanation has been proposed in the lead-acid battery literature where phosphoric acid is known to be an effective additive for suppressing OER. ${ }^{28}$ These results demonstrate the impact that buffer identity can have on the operation and activity of OER catalysts in acid and forecasts the need to consider the role of electrolyte in the development of active, stable, and earth-abundant OER catalysts. 
Material is based upon work supported under the Solar Photochemistry Program of the Chemical Sciences, Geosciences and Biosciences Division, Office of Basic Energy Sciences of the U. S. Department of Energy DE-SC0017619. T. P. K. acknowledges support from a Graduate Research Fellowship from the National Science Foundation. We thank Dr Matthew Nava for helpful discussions.

\section{Conflicts of interest}

There are no conflicts to declare.

\section{Notes and references}

1 N. S. Lewis and D. G. Nocera, Proc. Natl. Acad. Sci. U. S. A., 2006, 103, 15729-15735.

2 S. Chu and A. Majumdar, Nature, 2012, 488, 294-303.

3 T. R. Cook, D. K. Dogutan, S. Y. Reece, Y. Surendranath, T. S. Teets and D. G. Nocera, Chem. Rev., 2010, 110, 6474-6502.

4 D. Abbott, Proc. IEEE, 2010, 98, 42-66.

5 F. P. G. de Arquer, C.-T. Dinh, A. Ozden, J. Wicks, C. McCallum, A. R. Kirmani, D.-H. Nam, C. Gabardo, A. Seifitokaldani, X. Wang, Y. C. Li, F. Li, J. Edwards, L. J. Richter, S. J. Thorpe, D. Sinton and E. H. Sargent, Science, 2020, 367, 661-666.

6 B. A. Zhang, C. Costentin and D. G. Nocera, Joule, 2019, 3, 1565-1568.

7 M. Ma, E. L. Clark, K. T. Therkildsen, S. Dalsgaard, I. Chorkendorff and B. Seger, Energy Environ. Sci., 2020, 13, 977-985.

8 M. W. Kanan and D. G. Nocera, Science, 2008, 321, 1072-1075.

9 M. Dinca, Y. Surendranath and D. G. Nocera, Proc. Natl. Acad. Sci. U. S. A., 2010, 107, 10337-10341.

10 C. Costentin and D. G. Nocera, Proc. Natl. Acad. Sci. U. S. A., 2017, 114, 13380-13384.
11 M. Huynh, D. K. Bediako and D. G. Nocera, J. Am. Chem. Soc., 2014, 136, 6002-6010.

12 M. Huynh, T. Ozel, C. Liu, E. C. Lau and D. G. Nocera, Chem. Sci., 2017, 8, 4779-4794.

13 M. Blasco-Ahicart, J. Soriano-López, J. J. Carbó, J. M. Poblet and J. R. Galan-Mascaros, Nat. Chem., 2018, 10, 24-30.

14 R. F. Amlie and T. A. Berger, J. Electroanal. Chem. Interfacial Electrochem., 1972, 36, 427-433.

15 C. L. Farrow, D. K. Bediako, Y. Surendranath, D. G. Nocera and S. J. L. Billinge, J. Am. Chem. Soc., 2013, 135, 6403-6406.

16 C. N. Brodsky, D. K. Bediako, C. Shi, T. P. Keane, C. Costentin, S. J. L. Billinge and D. G. Nocera, ACS Appl. Energy Mater., 2019, 2, 3-12.

17 P. Du, O. Kokhan, K. W. Chapman, P. J. Chupas and D. M. Tiede, J. Am. Chem. Soc., 2012, 134, 11096-11099.

18 D. K. Bediako, A. M. Ullman and D. G. Nocera, Catalytic Oxygen Evolution by Cobalt Oxido Thin Films. in Topics in Current Chemistry, ed. H. Tuysuz and C. K. Chan, Springer Publishing AG, Switzerland, 2016, 173-213.

19 Y. Surendranath, D. A. Lutterman, Y. Liu and D. G. Nocera, J. Am. Chem. Soc., 2012, 134, 6326-6336.

20 G. Kwon, H. Jang, J. S. Lee, A. Mane, D. J. Mandia, S. R. Soltau, L. M. Utschig, A. B. F. Martinson, D. M. Tiede, H. Kim and J. Kim, J. Am. Chem. Soc., 2018, 140, 10710-10720.

21 Y. Arai and D. L. Sparks, J. Colloid Interface Sci., 2001, 241, 317-326.

22 E. Bae and W. Choi, J. Phys. Chem. B, 2006, 110, 14792-14799.

23 E. D. Laudadio, J. W. Bennett, C. M. Green, S. E. Mason and R. J. Hamers, Environ. Sci. Technol., 2018, 52, 10186-10195.

24 W. Stumm and R. Wollast, Rev. Geophys., 1990, 28, 53.

25 J. S. Geelhoed, T. Hiemstra and W. H. Van Riemsdijk, Geochim. Cosmochim. Acta, 1997, 61, 2389-2396.

26 D. D. Hansmann and M. A. Anderson, Environ. Sci. Technol., 1985, 19, 544-551.

27 L. Charlet, N. Dise and W. Stumm, Agric., Ecosyst. Environ., 1993, 47, 87-102.

28 M. P. Vinod, K. Vijayamohanan and S. N. Joshi, J. Power Sources, 1998, 70, 103-105. 